\title{
Evaluation of questionnaire on cancer family history in identifying patients at increased genetic risk in general practice
}

\author{
Virginia Leggatt, James Mackay, John R W Yates
}

Patients at increased genetic risk of breast or colorectal cancer who may benefit from screening can be identified from their family histories. ${ }^{12}$ For those at risk of colorectal cancer, colonoscopic surveillance reduces the incidence of disease. ${ }^{3}$ For those at risk of breast cancer, the results of mammographic screening are encouraging but more data are needed to confirm benefit. $^{4}$

Currently, patients with indicative family histories who consult their general practitioners are often referred to clinics for cancer genetics. Others with similar family histories who are less aware of the familial nature of these cancers or of the availability of screening do not seek advice.

If improving knowledge about the genetics of familial cancers and other common diseases is to benefit all patients and not just those who are better informed, strategies need to be developed to identify those at risk. We investigated the feasibility of using a postal questionnaire to identify patients in a general practice at increased genetic risk of breast or colorectal cancer.

\section{Subjects, methods, and results}

Information about the study was sent to all patients aged 35-65 years who were registered with one general practice. Altogether 1460 out of $2265(64 \%)$ responded to the letter of invitation, but $500(22 \%)$ declined to take part. The remaining 960 patients $(42 \%)$ agreed to take part and were sent a questionnaire requesting details of first degree, second degree, and more distant relatives known to have had cancer and for their age at diagnosis; 666 patients (29\%) completed the questionnaires. Compared with the practice population, a higher proportion of respondents were women $(62.2 \%$ (414 out of 666 ) compared with $50.2 \%$ (1138 out of 2265 ), $\chi^{2}=37.8$; $\mathrm{P}<0.001)$ and a lower proportion were aged 35-44 (30.2\% (201 out of 666) compared with 40.7\% (921 out of 2265), $\left.\chi^{2}=30.3 ; \mathrm{P}<0.001\right)$.

The completed questionnaires were assessed by a general practitioner (VL), applying criteria in use in local clinics for cancer genetics at the time of the study to identify patients at sufficiently increased risk of breast or colorectal cancer to offer screening (screening criteria available from us).

Six hundred and twenty patients not meeting these criteria (lower risk group) were informed of this by letter; 46 patients reporting potentially indicative family histories were evaluated further to confirm the details and validate diagnoses in relatives. Most were seen for interview, but in a few cases uncertainties were resolved by telephone. Finally, 29 patients were assessed to be at significantly increased risk (higher risk group): 18 met local screening criteria and 11 were deemed at sufficient risk to be offered screening after discussion with a clinical geneticist (JM or JRWY) (figure); of these patients 14 had previously received genetic advice.

The remaining 15 patients were offered referral to a clinic for cancer genetics, and one was found at screening to have an impalpable breast cancer. Twelve of those offered referral had never previously discussed their family history of cancer with their general practitioner.

\section{Comment}

An estimated 1.6\% of women aged 35-49 years fulfil the screening criteria for breast cancer used in this study. ${ }^{5}$ The questionnaire identified 3 out of 198 $(1.5 \%)$ female respondents in this age group meeting the criteria, which is in line with this prediction, but the numbers are too small to draw conclusions. Estimates of the proportion of the population fulfilling the screening criteria for colorectal cancer are not available.

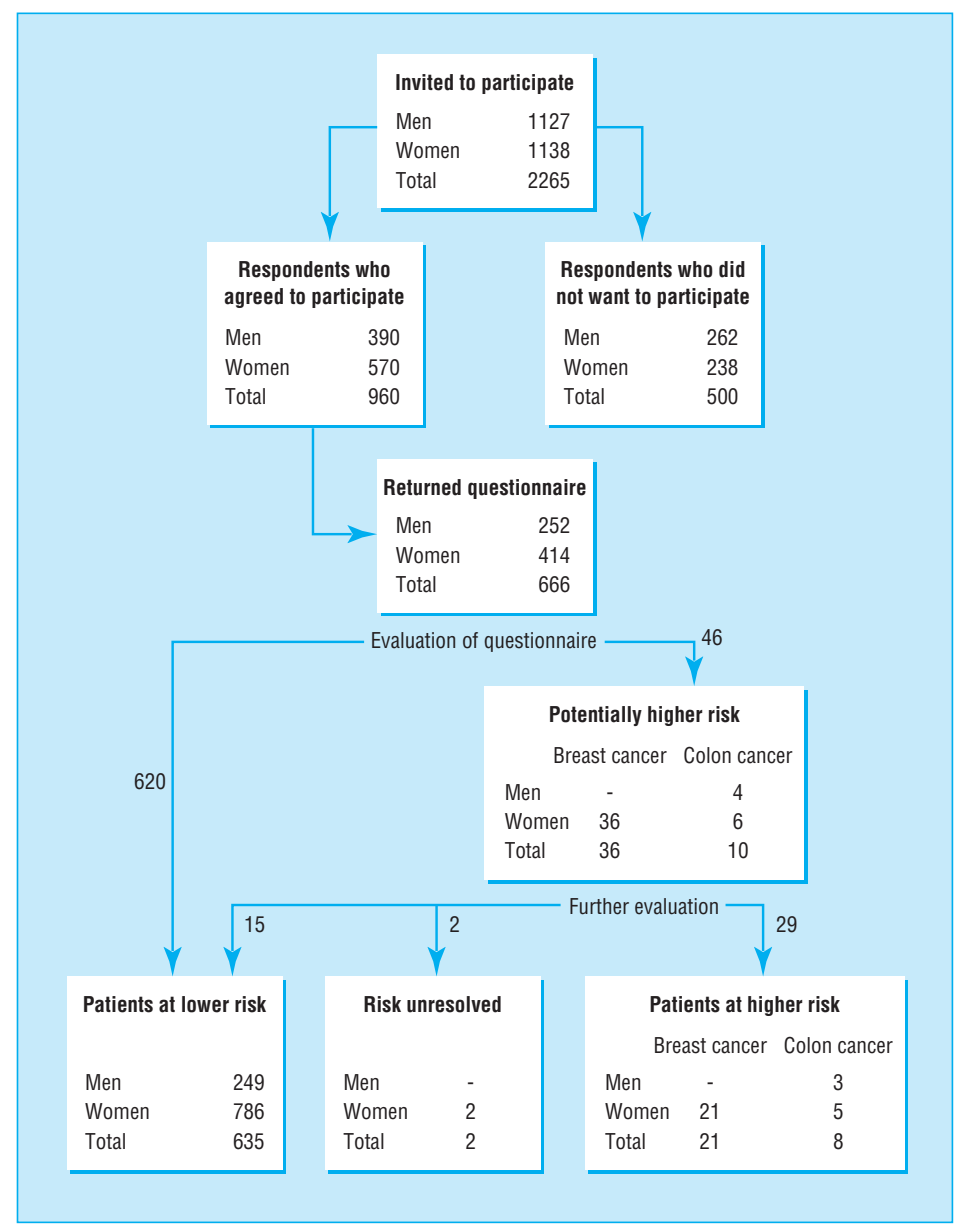

Numbers, sex, and classification of cancer of patients at each stage of the study

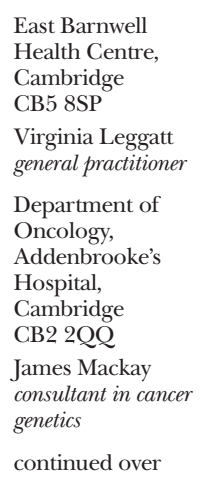

BMJ 1999;319:757-8 
Department of Medical Genetics, University of

Cambridge,

Addenbrooke's

Hospital,

Cambridge

CB2 2QQ

John R W Yates

university lecturer

Correspondence to: Dr Leggatt
This study shows that a self completed questionnaire is a useful instrument for obtaining family histories of cancer to identify patients at increased genetic risk. However, the response rate was only $29 \%$ when it was sent by post. A better response might be achieved if questionnaire was used in another setting, for example, during registration of new patients.

We thank all the patients who participated in this study and the doctors and staff at East Barnwell Health Centre, Cambridge, for their support and encouragement. We thank Paul Pharoah for kindly allowing us to base the family history questionnaire on one that he had already developed. We thank Steve Jones for help with computing and Elaine Farrell for secretarial assistance. We thank Hilarie Bateman for help with planning the study and Chris Todd for statistical advice. We also thank Martin Bobrow, Ann Louise Kinmonth, and Fawzia Khan for their helpful comments.

Contributors: VL had the original idea for the study and was responsible for its execution. VL and JRWY jointly designed the investigation, undertook the data analysis, and drafted the paper. JRWY and JM provided specialist advice on the risk assessment of patients with potentially indicative family histories of colorectal and breast cancer. JM contributed to the study design, interpretation of the data, and revision of the paper. All authors approved the final version for publication. VL is guarantor.

Funding: The study was funded by the Oxford and Anglia Regional Research and Development Fund.JM is funded by the Cancer Research Campaign.

Competing interests: None declared.

1 Pharoah PDP, Stratton JF, Mackay J. Screening for breast and ovarian cancer: the relevance of family history. Br Med Bull 1998;54:823-8.

Dunlop MG. Colorectal cancer. BMJ 1997;314:1882-5.

3 Jarvinen HJ, Mecklin JP, Sistonen P. Screening reduces colorectal cancer rate in families with hereditary non-polyposis colorectal cancer. Gastroenterology 1995;108:1405-11.

4 Lalloo F, Boggis CR, Evans DG, Shenton A, Threlfall AG, Howell A. Screening by mammography, women with a family history of breast cancer. Eur J Cancer 1998;34:937-40.

5 Mackay J. The role of genetic testing in breast cancer by the year 2000. Cancer Treat Rev 1997;23:S13-22.

(Accepted 24 May 1999)

\section{A meeting which changed me There is another way}

I first encountered Jean-Claude in 1976 during a meeting organised by Le Comité de Défense contre l'Alcoolisme (national antialcoholism defence committee). The meeting comprised doctors, lawyers, social workers, and representatives from ex-alcoholics organisations, all concerned with the problem of alcohol. The end result had been rather disappointing and, as we left, Jean-Claude invited me to accompany him the following Wednesday to his Alcoholics Anonymous meeting. I had never heard of AA, and immediately accepted his offer.

I had just completed a study on sclerosing oesophageal varices and demonstrated that it had no effect on a patient's survival. After that I began to pay attention to the patients who had an alcohol problem. I noticed that this attention caused many of them to reduce or even stop the intake of their favourite beverage. And I also noticed that those who abstained had lower morbidity and death rates. I was convinced that individual attention was more important than endoscopic procedures in caring for alcoholic patients, especially those with cirrhosis and portal hypertension.

So, that Wednesday, he stood on the pavement awaiting me. Together we entered a large square, gloomy room, and soon a dozen people were sitting around. Each of them was well dressed, even elegant, except for one woman of totally indeterminate age, as thin as a rake, and who was silently crying. I remember it as though it were yesterday. Everybody introduced themselves with: "Hello. My name is Paul, Ann, Jean-Claude, Henry, I am an alcoholic, sober today."

The theme of the meeting was "How to change one's behaviour." Everyone was waiting his or her turn to speak. Nobody cut in on anyone else; people were extremely attentive to each other; the courtesy was palpable; and nobody was sermonising, merely relating his or her own personal experience in identical circumstances. The woman was now sobbing, she was unable to say one word. Somebody said to her:
"The important thing is your being here; as each hour passes, just try not to drink that first glass. If you get into trouble, just call." The meeting ended exactly on time after ninety minutes, with a short prayer.

I attended many such meetings. Within three months the sobbing woman completely changed. She looked 20 years younger, put on 15 kilos and acquired a nice shape. She was smiling and chatting, and looked rather pretty. Before discovering AA, her life had been a nightmare and worse, a journey to hell. I had also changed. I learnt how to diagnose alcoholism at an early stage before the onset of severe complications, and how to convince reluctant people to try to attend AA meetings. I approached AA members and they agreed to run a group in the unit for which I was responsible. Together we developed a flourishing, cooperative team.

From the age of 5 , I had been an agnostic, up in arms against my family, society, God, and myself.

Thanks to AA, I came to understand that if hell existed on earth then there was also a secret kingdom in which the wild beast could be transformed into the lamb, murderers into righteous citizens, and rebels into law observing individuals. This is the way I was christianised by alcoholics, but that, as Rudyard Kipling would have said, is another story.

Patrice Metayer, head of the gastroenterology and medicine department, Dieppe, France

We welcome articles up to 600 words on topics such as A memorable patient, A paper that changed my practice, My most unfortunate mistake, or any other piece conveying instruction, pathos, or humour. If possible the article should be supplied on a disk. Permission is needed from the patient or a relative if an identifiable patient is referred to. We also welcome contributions for "Endpieces," consisting of quotations of up to 80 words (but most are considerably shorter) from any source, ancient or modern, which have appealed to the reader. 